\title{
A LÓGICA DO CONTEÚDO NO REINO DAS SOMBRAS: O INÍCIO E O PRINCÍPIO DA CIÊNCIA DA LÓGICA DE HEGEL
}

\author{
THE LOGIC OF CONTENT IN THE REALM OF SHADOWS: BEGINNING AND \\ PRINCIPLE OF HEGEL'S SCIENCE OF LOGIC
}

\author{
GUILHERME FERREIRA ${ }^{1}$ \\ Universidade Federal de Minas Gerais (UFMG) - Brasil \\ guilhermecicm@ufmg.br
}

\begin{abstract}
RESUMO: O artigo examina a conexão existente entre a concepção hegeliana de início e princípio e a função que esses conceitos cumprem no interior da Ciência da lógica de Hegel. Primeiro, eu busco situar em geral o que Hegel considera como sendo o início e o princípio da Ciência da Lógica. Segundo, procuro analisar como o princípio geral de justificação do método lógico é uma determinação processual do conteúdo [Gehalt] por meio da exposição de conteúdos [Inhalte] lógicos. Terceiro, eu procuro examinar em que sentido se pode afirmar que a Fenomenologia do espírito é o princípio de pressuposição do método lógico. A hipótese central deste artigo é a de que a lógica de Hegel é essencialmente uma lógica do conteúdo [Gehalt], a ideia lógica imanente à exposição de conteúdos [Inhalte] lógicos.
\end{abstract}

PALAVRAS-CHAVE: Hegel. Ciência da Lógica. Início. Princípio.

ABSTRACT: This paper examines the connection between the Hegelian conception of beginning and principle and the function that these concepts fulfill within the Hegel's Science of Logic. First, I try to situate in general what Hegel considers to be the beginning and the principle of the Science of Logic. Second, I seek to analyze how the general principle of justification of the logical method is a procedural determination of content [Gehalt] through the exposure of logical contents [Inhalte]. Third, I seek to examine in what sense one can affirm that Phenomenology of the Spirit is the principle of assumption of the logical method. The central hypothesis of this paper is that Hegel's logic is essentially a logic of content [Gehalt], the logical idea immanent in the exposure of logical contentes [Inhalte].

KEYWORDS: Hegel. Science of Logic. Beginning. Principle.

\footnotetext{
${ }^{1}$ Doutorando em Filosofia pela Universidade Federal de Minas Gerais (UFMG). O presente trabalho foi realizado com apoio da Coordenação de Aperfeiçoamento de Pessoal de Nível Superior - Brasil (Capes e Capes-Print).
} 


\section{INTRODUÇÃO ${ }^{2}$}

O sistema da lógica é o reino das sombras, o mundo das essencialidades simples, libertado de toda concreção sensível. O estudo dessa ciência, a estadia e o trabalho nesse reino de sombras é a formação absoluta e a disciplina da consciência. Impulsiona aí uma ocupação afastada das intuições e dos fins sensíveis, dos sentimentos e do mundo meramente opinado da representação (HEGEL. Ciência da lógica, 2016, p. 61-62). ${ }^{3}$

Esta é uma imagem importante para a compreensão do sistema da lógica de Hegel: o reino das sombras. Pois, enquanto a aparência sensível dos objetos em geral indica o anverso da efetividade [Wirklichkeit] das coisas [Dinge], as sombras, além disso, apontam para o lado negativo, reverso à aparência positiva. Enquanto reflexo, a sombra é uma expressão em movimento de algo que, frente aos olhos, aparece como estático. Ela é, portanto, imagem refletida em movimento. Diferente de outro objeto sensível qualquer - o qual tende imediatamente a ocultar de si a sua negatividade e movimento por meio da sua materialidade maciça - a sombra não pode ocultar de si nada para além da negatividade contida em si daquilo de que ela é feita instante, momento: a própria coisa que ela projeta por meio da interceptação da luz. Mas, não é nesse sentido que Hegel fala das sombras: enquanto objeto sensível ou coisa [Ding] dada. Ele está se referindo a algo mais amplo, a um "reino de sombras" enquanto metáfora do "mundo de determinações essenciais": a Lógica. Hegel está se referindo a uma constelação de coisas cujo conceito é autodeterminado pela própria gramática constitutiva das coisas, assim como pela própria estrutura e dinamismo do pensamento racional. Nesse sentido, segundo Robert Pippin (2019, p. 29), seria adequado, inclusive, pensar a Ciência da lógica (considerando a totalidade dessa obra) como "um esclarecimento reflexivo que nos permite ver o mundo nas sombras, ver a sua estrutura de inteligibilidade de uma forma que nunca existe isolada como tal".

Isso não quer dizer, porém, que a coisa [Ding] sensível não possa ser inteligível em sua singularidade e efetividade de modo racional. Todavia, essa é uma questão a ser pensada no âmbito da filosofia real [Realphilosophie], na qual um dos papeis centrais (considerando a estrutura do sistema hegeliano) seria justamente o de "desenvolver a forma encarnada destas formas lógicas de tornar inteligível" (id.) o mundo efetivo. A coisa que se faz objeto da lógica de Hegel não

\footnotetext{
${ }^{2}$ Agradeço aos comentários, críticas e sugestões propostos pelos pareceristas anônimos, os quais me permitiram reparar erros, aperfeiçoar a interpretação e avançar na pesquisa. Agradeço também à Capes e à Capes-print, cujas bolsas garantem a continuidade desta pesquisa.

${ }^{3}$ HEGEL, G.W.F. Ciência da lógica 1. A Doutrina do ser. Trad. Chritian G. Iber, Marloren L. Miranda e Federico Orsini. Coordenador: Agemir Bavaresco. Colaboradores: Michela Bordignon, Tomás Farcic Menk, Danilo Costa e Karl-Heinz Efken. Petrópolis, RJ: Vozes, 2016. As citações são feitas de acordo com a edição brasileira completa da Ciência da lógica de Hegel, a qual é composta de três volumes. As citações do texto original indicam modificações de tradução feitas por nós, cujo objetivo foi simplesmente a adequação de regências, com base naquilo que pareceu mais adequado às hipóteses de interpretação deste texto, sempre buscando não perder de vista o sentido tanto do texto original quando da sua tradução oficial aqui utilizada. As citações do original são feitas com base na edição Suhrkamp das obras de Hegel, referida pelo nome do autor (HEGEL, G.W.F. Werke 5. Wissenschaft der Logik. Frankfurt am Main: Suhrkamp, 1986 ss.) seguido do ano da publicação e da página. As citações das edições Gesammelte Werke são referidas, igualmente, pelo nome do autor, seguido do ano da publicação e da página.
} 
é a coisa singular, mas a coisa [Sache] em sua processualidade interna, isto é, a coisa em sua essência e conceito, algo que certamente passa desapercebido aos olhos do sujeito, já que nesta estrutura processual a gramática do todo do ser se identifica com a gramática do todo do pensamento. Em outras palavras, não se trata da coisa pensada como simplesmente coisa finita, como forma [Form] que possui um conteúdo [Inhalt] (objeto de percepção ou, tão somente, determinação de reflexão), mas, antes, da coisa observada em si e para si, enquanto substância material persistente e resistente frente as suas diversas nuances qualitativas e quantitativas (para usar um exemplo do item 'medida', da terceira seção da 'Doutrina do ser'). Esse é o reino das sombras o qual Hegel se refere: o mundo da essencialidade conservada no todo do ser e no todo do pensar.

A Ciência da lógica, enquanto gramática do mundo das determinações essenciais, tem, portanto, como conteúdo [Gehalt] autêntico e método lógico "a coisa ela mesma” [die Sache selbst]. Como nos lembra Kervégan (2008, p. 77), essa é a expressão utilizada por Hegel para designar o conteúdo da Lógica. Se, por um lado, estamos de acordo com o intérprete francês, de que "essa coisa [Sache] não é, portanto, uma coisa [Ding]: é principalmente 'o conceito das coisas"' (id.), por outro lado, entretanto, precisamos acrescentar que esse conteúdo [Gehalt] nuclear da Lógica não é, igualmente, um simples conteúdo [Inhalt] singular: é principalmente o conteúdo total, e não a proporção (substância) do todo; é o "conteúdo" conceituado como totalidade de "conteúdos". Em outras palavras, o conteúdo da Lógica pressupõe nada mais que a inexistência de pressuposto de todo conteúdo sensível. Trata-se de um conteúdo cuja identidade é uma totalidade, um reino, "afastado das intuições e dos fins sensíveis, dos sentimentos e do mundo meramente opinado da representação" (HEGEL, 2016, p. 62).

A Lógica do conteúdo no reino das sombras não pode, com isso, ser entendida como lógica formal, no sentido de um Formalismus hiperconcentrado na forma [Form] em detrimento de um conteúdo. O formal da Lógica de Hegel, contrariamente ao modo como se o toma comumente, "tem de ser pensado como muito mais rico dentro de si em determinações e conteúdo, e também como dotado de uma eficácia infinitamente maior sobre o concreto" (HEGEL, 2018, p. 56). À vista disso, "a lógica é a ciência da forma absoluta" (ibid., p. 55), o formal verdadeiro, que contém nele próprio o conteúdo [Inhalt adequado a sua forma e que, assim, é conteúdo [Gehalt] total, conteúdo que não "permanece isolado em sua singularidade" (HEGEL, 1995, p. 70), mas que "se representa afetado pelo tempo, fluindo nele e mutável" (ibid., p. 71).

O objetivo deste texto será, em geral, demostrar o sentido dessa noção de "conteúdo total" o que implicará, em última instância, a compreensão da lógica de Hegel como lógica do conteúdo. Veremos ao final deste trabalho que o reino das sombras nada mais é senão que o reino de Deus, "o reino do puro pensamento", cujo conteúdo [Inhalt é a exposição processual do conteúdo [Gehalt], ou da "ideia lógica" (o pensar desse pensamento). Hegel já nos adverte, desde o início, que o conteúdo de sua Lógica "é a apresentação de Deus, tal como ele é em sua essência eterna antes da criação da natureza e de um espírito finito" (HEGEL, 2016, p. 52). Todavia, exatamente por ser a Lógica a "exposição de Deus", ou, nas palavras de 
Kervégan (2008. p. 76), a exposição da "essência eterna", que compreende o todo do ser ou mesmo "a totalidade dos possíveis", o método de exposição desta "gramática de Deus" coincide com o seu saber. Essa identidade entre essência e existência, infinito e finito (ou melhor, esse automovimento da essência eterna que, processualmente, se determina para uma existência ou para um ser), implica a questão de saber qual a significação do método lógico em Hegel. Por outro lado, precisamos questionar, igualmente, sobre qual seria o início dessa lógica circular, dessa espécie de "fita de Möbius", na qual, de um lado, o ser apenas se torna si mesmo no limite do desprendimento de si e, de outro lado, esse limite, na verdade, acaba por descortinar o processo infinito do ser rumo ao seu conceito, o seu princípio. Cabe perguntar, portanto, qual a maneira adequada de compreensão tanto do "início" quanto do "princípio" da Ciência da lógica.

Segundo Hegel, a questão toda a respeito do método ${ }^{4}$ da ciência pura é a de "[saber] como um tal absoluto entra no saber pensante e no enunciar desse saber" (HEGEL, 2016, p. 80). E o presente artigo procura analisar justamente como Hegel pensa em geral o método da lógica e, de modo específico, como ele responde as diversas indagações que de modo oportuno aparecem a respeito do princípio e do início da ciência pura. À vista disso, o nosso texto se divide em três momentos. Primeiro, procuramos situar em geral o que Hegel considera como sendo o início e o princípio da Ciência da lógica. Segundo, procuramos analisar como o princípio geral de justificação do método lógico é uma determinação processual do conteúdo [Gehalt] por meio da exposição de conteúdos [Inhalte] lógicos. Terceiro, procuramos examinar em que sentido se pode afirmar que a Fenomenologia do espírito é "o princípio" de pressuposição do método lógico. A hipótese central deste trabalho é a de que a lógica de Hegel é essencialmente uma lógica do conteúdo [Gehalt], a "ideia lógica" (princípio) imanente à exposição de conteúdos [Inhalte] lógicos o que, nas palavras de Hegel, corresponderia à afirmação de que "a pura mediação ou negatividade absoluta é imediata" (HEGEL, 1986b, p. 23).

\footnotetext{
${ }^{4}$ Hegel compreende o método como sendo um movimento intrínseco ao próprio desenvolvimento do conceito, de modo que método e saber, objeto e sujeito não se contrapõem de modo irreconciliável. Segundo Hegel, "o método é o movimento da infinita universalidade, no sentido interno e externo, como força absolutamente infinita, que nenhum objeto enquanto se apresenta como exterior, afastado da razão e independente dela, poderia oferecer resistência, oferecer diante dela uma natureza particular e recusar-se a ser compenetrado por ela. Por isso, o método é a alma e a substância, e uma coisa que só é conceituada e conhecida em sua verdade quando está integralmente submetida ao método; ela é o método de cada coisa mesma, porque a sua atividade é o conceito. Esta é a significação verdadeira da universalidade, segundo a universalidade da reflexão tudo é tomado como método; segundo a universalidade da Ideia ele é o meio e o sentido do conhecimento, como o subjetivo autoconhecimento do conceito, como a maneira e sentido objetivo, ou muito mais a substancialidade das coisas, ou seja, dos conceitos, enquanto a representação e a reflexão aparecem em outro" (HEGEL, 1986b. pp. 551-552). Em Hegels Logik, Klaus Hartmann reforça essa compreensão ao explicar o seguinte: "o método é o percurso de desenvolvimento do conceito, no qual o conceito se mantém objetivado, e a forma e a direção, como se coloca este desenvolvimento. Ele é o movimento dialético de forma e conteúdo, o movimento categorial do conceito em direção ao saber de si mesmo" (HARTMANN, 1999, p. 444).
} 


\section{COM O OUE PRECISA SER FEITO O INÍCIO DA CIÊNCIA?}

Perguntar sobre o modo como deve ser pensado o início da ciência é ao mesmo tempo colocar-se a par do seu princípio, isto é, do seu alicerce ou base de sustentação. Esta é uma consideração fundamental para Hegel quando o assunto é a definição de ciência. A pergunta sobre o início da ciência, por onde ela deve começar, implica necessariamente saber da estrutura sobre a qual este início se constitui. Para Hegel, esta questão é um problema relativamente novo para a filosofia de sua época e que, por isso mesmo, precisou ser colocada como objeto de uma incansável consideração, sobretudo, em relação à questão sobre se tal início "deveria ser algo imediato ou mediado" (HEGEL, 1986a, p. 65). Isto é, se o ponto de partida do conhecimento deveria ser um dado pura e simplesmente imediato ou se seria uma mediação aparentemente imediata. É claro que colocada de modo simples esta é uma indagação mal formulada, uma vez que o seu conteúdo (a subjetividade e a objetividade) expressa a unilateralidade com que a questão do imediato e do mediado é posta. Formulada nestes termos, para o filósofo de Stuttgart, é fácil mostrar que o início da filosofia não pode ser nem uma coisa nem outra (HEGEL, 2016, p. 69), ou seja, nem o mediado nem o imediato, e é deste modo que ambos os modos encontram seu princípio de "contradição dialética". 5

O que Hegel quer mostrar com esta rejeição expressa na unilateralidade do par mediado e imediato, é que o cerne do problema do conhecimento encontrase postulado como princípio e não simplesmente como início, enquanto algo que se inicia mera e simplesmente por meio de categorias abstratas próprias ao filosofar. Mas qual a diferença estrutural entre o início e o princípiơ? Para Hegel, nem todo início é constituído por um princípio objetivo, por uma base forte de sustentação a partir da qual o início pode encontrar a sua referência fundacional. Já o princípio, se configura por si só como uma base sólida e, por isso mesmo,

\footnotetext{
5 A contradição dialética não pode ser confundida com a contradição propositiva da lógica tradicional aristotélica, bem como ela também não deve ser entendida em termos puramente formais, isto é, segundo a lógica do entendimento separador (tal como é pensado na lógica transcendental de Kant), o qual procura afastar de si toda contradição. Ao contrário disso, a contradição dialética deve ser considerada o motor do pensamento especulativo já que, segundo Hegel, "ela é a raiz de todo o movimento e toda vitalidade". Marcos Müller (2019, pp.123-124) trata em detalhes deste assunto e conclui não apenas que a contradição é o motor do pensamento lógico, mas, igualmente, o seu fundamento (cf. MÜLlER, 2019, pp. 123-149). A interpretação de Müller corrobora a intepretação que Wolff (1981, p. 19) faz do conceito de contradição em Hegel. Wolff acredita que Hegel não dá muita atenção ao conceito de contradição proposicional, pois ele aposta mais numa relação objetiva entre determinações diferentes. Sobre isso cf. WOLFF, 1981, pp. 18-20. Michela Bordignon (2018, p. 249) segue nesta mesma direção ao comparar a dialética de Hegel com o dialeteísmo de Graham Priest, e conclui que a razão especulativa "é incontraditória, mesmo quando pensa a contradição, por que não faz nada além de seguir o desenvolvimento intrínseco das determinações lógicas". Sobre isso cf. BORDIGNON, 2018, pp. 233-52; BORDIGNON, 2015. Hösle (2007, p. 190) identifica três formas de contradição distintas, as quais, segundo ele, podem ser pensadas como contraposição ao conceito hegeliano de contradição: a) "o princípio lógico argumentativo da contradição" (uma teoria é falsa se ela tem contradições); b) as falsas "proposições que tem a estrutura 'A e não-A'"; c) "não pode haver nada que se contradiga". Para Hösle, Hegel é da opinião de que tudo se contradiz e, nesse sentido, ele "aceita a versão lógicoargumentativa [...], rejeita a versão ontológica desse princípio [...], e distingue duas formas de contradição, uma negativa e outra positiva" (cf. HÖSLE,2007, p. 190). Wandschneider (1995, pp. 17-19) relaciona a contradição com a tese de Hegel sobre a ausência de pressuposição como o caráter central da ciência pura. Sobre isso cf. WANDSCHNEIDER, 1955, pp. 17-19.
} 
"certamente também expressa um início, mas menos um início subjetivo do que um objetivo, o início de todas as coisas" (id.).

Sendo o princípio um início objetivo de todas as coisas ele também é "um conteúdo [Inhalt] de algum modo determinado" (HEGEL, 1986a, p. 65). Ao contrário do início que, enquanto tal, "permanece inobservado e indiferente como algo subjetivo, como um modo casual de introduzir uma preleção" (id.), o princípio "se desloca para a determinação do conteúdo" (ibid., p. 66). Em outras palavras, no princípio, ao contrário do início, parece residir a questão [Sache] fundamental acerca do conhecimento científico: "o interesse sobre o que seja o verdadeiro, $o$ fundamento absoluto de tudo" (HEGEL, 2016, p. 69). Para Hegel, entretanto, postular o conteúdo de todas as coisas como pilar de sustentação para a progressão acerca do saber não pressupõe a fusão entre subjetividade e objetividade, mas antes a distinção e a relação necessária entre as duas. Hegel dá exemplo disso ao afirmar que o problema da aporia moderna em torno do início da ciência sempre manteve em si uma necessidade ulterior inobservada por aqueles que trataram "dogmaticamente da prova do princípio ou, ceticamente, da descoberta de um critério subjetivo contra o filosofar dogmático" (HEGEL, 2016, p. 69). Esta necessidade ulterior diz respeito ao modo subjetivo do atuar científico. Ou seja, se a ciência se interessa por certo conteúdo [Inhalt] objetivo, mas no seu desenvolvimento metodológico assume o desempenho subjetivo como princípio, então a subjetividade passa a fazer parte e é assimilada como elemento da verdade objetiva e, se assim o é, torna-se inevitável a necessidade [Bedürfnis] de que "o método seja unido ao conteúdo, a forma ao princípio" (ibid., p. 70). Ou seja, se todo conhecimento objetivo implica um sujeito, logo torna-se condição sine qua non a unificação entre a forma da lógica interior e o conteúdo objetivo determinado.

Nesse sentido, o imediato e o mediado devem ser compreendidos como determinações formais universais, as quais, em se tratando do saber, adquirem a forma determinada de saber imediato e saber mediado. Todavia, a natureza do saber científico não é um pressuposto, e sim um processo a ser desenvolvido. Assim, o imediato que se anuncia como início na Ciência da lógica não se refere ao imediato sensível - seja o da certeza sensível da Fenomenologia do espírito, seja o da coisa [Ding] perceptível -, mas sim a coisa ela mesma [die Sache selbst], isto é, a coisa tal como ela é em seu conceito. O início, portanto, é início lógico. Enquanto ciência pura, a Lógica tem o seu começo na coisa mais simples (imediata) e mais universal (mediada) que podemos pensar: o ser puro. Esse ser puro, ser simples (sem nenhuma outra determinação), todavia, já é uma mediação do pensamento puro e, portanto, uma coisa invisível, abstrata, universal, que já está pressuposta como saber, saber puro. Assim, a ciência pura, em seu começo, deve ser entendida no limite da questão em que ela contém o pensamento puro e que esse pensamento é a própria coisa ela mesma [die Sache selbst], ou, ao contrário, que a coisa ela mesma é igualmente o pensamento puro.

Bernard Bourgeois (2004, p. 307) defende que a expressão, ou o movimento de exteriorização desse pensamento puro e desse ser puro (os quais só encontram a sua verdade internamente: no pensamento do pensamento e na coisa enquanto 
conceito ela mesma) é ainda uma espécie de sensibilização, a qual sustenta a diferença formal exigida pelo saber lógico, "mas essa sensibilização nega-se imediatamente nela mesma, desaparece ao aparecer, sem tornar opaco portanto o sentido puro que ela deve dizer" (id.). Bourgeois compara essa sensibilização do pensamento puro ao signo linguístico, o qual, enquanto perfeição sonora, logo desvanece e, assim, possui um significado na sua própria "insignificância sensível". Nesse sentido, Bourgeois (2004, p. 307) entende que a exteriorização na Lógica de Hegel significa o auto-engendamento da ideia absoluta por meio do discurso lógico.

Ao estabelecer o início lógico como início absoluto, isto é, como início total - cujo campo de atuação é a interioridade e a universalidade do pensamento como coisa [Sache], e o campo de expressão é o outro de si mesmo, isto é, "o simples imediato, exterior e singular em face do mediatizado" (HEGEL, 1995, p. 75) Hegel, ao mesmo tempo, demonstra a alteração do sentido com que, comumente, pensamos o imediato-sensível. Mediante ao pensamento puro e ao ser puro do começo, "algo se alterou na maneira como o conteúdo é inicialmente sensação, intuição e representação", todavia, nos garante Hegel, "é somente por intermédio de uma alteração que a verdadeira natureza do objeto chega à consciência" (id.). Nesse sentido, o universal do ser, a sua essência e conceito, não é algo que "se vê nem se ouve", não é algo "para os sentidos, mas só para o espírito e pensamento", assim como o gênero e as leis que regem o movimento dos corpos celestes não são "coisas escritas no céu", mas experienciadas pelo saber. Trata-se, em última instância, "de um absoluto pelo qual tudo o mais é produzido" (id.).

Assim, o início do saber científico precisa considerar tanto o seu caráter lógico interior como o seu princípio de atuação, quanto precisa exteriorizar esta gramática do reino das essencialidades, no sentido de escrevê-la e inscrevê-la, de modo processual, através das "determinações de reflexão" - até o "limite" de sua evidenciação como ideia (conceito do conceito), e da encarnação dessa ideia lógica na filosofia real. O ser, o nada, o devir, o uno, o múltiplo, etc., são as categorias iniciais desse processo de escrita do pensamento puro. O seu começo se dá, como já foi dito, com a imediatidade simples, o ser puro, todavia, a característica processual desse ser é o "desdito", no sentido em que é "contradito" pelo seu oposto, o não-ser. Assim, no início, o ser só pode ser dito ou escrito de modo amplo, se ele imediatamente passa ao seu outro, o nada que, sendo igualmente inexprimível, passa ao vir a ser: a sua base de apreensão imediata.

Ora, se este "ser-desdito" só pode ser apreendido como vir-a-ser, então nos cabe perguntar: seria o vir-a-ser (e não o ser puro), a categoria de início da Lógica? A resposta a essa questão precisa considerar que Hegel antes de examinar, no início da Lógica, o ser determinado (ser-aí), ele considera o ser indeterminado em sua inteireza (o ser puro, o nada e o devir) como a base de dedução do ser determinado, de modo que a mediação se estabelece como anterior àquilo que ela mediatiza (o ser aí). Assim, por um lado, a verdade do ser puro (o vir-a-ser) é considera por Hegel como a categoria inicial, mas, por outro lado, o ser-aí também é considerado o início lógico (base para as demais categorias da lógica). Essa "duplicidade" do início lógico é amplamente justificada por Hegel. 
Ao examinar o início lógico, Hegel considera que, em primeiro lugar, "o ser é o conceito somente em $s \hat{\imath}$ ', ser indeterminado, e que as suas determinações ulteriores são "determinações essentes" (HEGEL, 1995, p. 173). Enquanto ser indeterminado, ser simples, ele é "uma fundação que se anula a si própria, que se mostra não ser verdadeiramente a fundação" (HEGEL, 2015, p. 723), na medida em que é pura abstração, vazia de conteúdo. Assim sendo, o início é algo que ainda não é, mas que deve ser alguma coisa. Isto é, "o início não é o nada puro, mas um nada do qual algo deve sair; o ser, portanto, também já está contido no início. O início contém, portanto, ambos, ser e nada; é a unidade de ser e nada" (HEGEL, 2016, p. 76). O ser e o nada também são elementos que se distinguem um do outro, pois se o início ainda não-é, mas caminha em direção ao seu oposto (o ser), então o início antes de tudo é um ser caracterizado como unidade distinta de ser e não-ser. Por outro lado, o início também é uma unidade indistinta entre ser e não-ser, já que ele é um não-ser que passa a ser algo na medida em que nãoé. O início, pois, é o ser tanto como unidade distinta quanto como unidade indistinta.

Temos aqui, segundo Hegel, um "movimento eleático do pensamento" e, para progredir na ciência é preciso lidar com ele. Por um lado, "pode-se descobrir que ele não está suficientemente fundamentado, e querer reforçá-lo ainda mais, mas desta forma caminha-se como caranguejo e não se avança” (HEGEL, 2015, p. 723). Por outro, pode-se descobrir que "o vir-a-ser é a verdadeira expressão do resultado de ser e de nada, enquanto sua unidade"; não a unidade no sentido de uma unificação simples, "enquanto relação-a-si, carente-de-movimento", mas sim a unidade enquanto "o desassossego em si" (HEGEL, 1995, p. 183). A inquietude, o vir-a-ser é, portanto, o início "procedural" (que começa, continua e se mantém como base) do desenvolvimento da Ciência da lógica. Todavia, enquanto base de sustentação, esse vir-a-ser é, ao mesmo tempo, capaz de conduzir a algo determinado, o ser-aí, o qual é a unidade sossegada (no sentido de unilateral e finita). Por outro lado, porquanto "unilateral e finito", o ser-aí é também um essente, isto é, uma qualidade deduzida do vir-a-ser: o ser aí é um "vindo-a-ser", diz Hegel.

O resultado do processo do vir-a-ser não é, pois, "o nada vazio, mas o ser idêntico à negação" (HEGEL, 1995, p. 186). Esta é a primeira derteminação do seraí: um essente, uma qualidade imediatamente determinada, que possui em si a negação como germe de sua determinação, assim como de sua mutabilidade. Dito de outro modo, a negação a qual possui o ser-aí é uma negação junto dele (o ser outro), imediatamente idêntica a si (e que não lhe sobrevém de fora), e isso é o que se chama, segundo Hegel, limite: "somente como limitado Algo é o que é". Mas esse limite possui uma face tanto real [Realität] quanto ideal: de um lado, o limite é a realidade do ser-aí (finitude), mas, de outro lado, o limite é também a negação, o ser outro, do ser-aí (infinitude). Isto é, a natureza do ser aí finito é o "ser Outro de si mesmo" e, assim, a sua alteração (infinitude), "desde a sua origem". Portanto, "o alterar-se reside no conceito do ser-aí, e a alteração é só a manifestação do que o ser aí é em si” (ibid., p. 189). A infinitude não é exterior a finitude (não é a má infinitude), mas sim a base constitutiva, a idealidade da finitude do ser-aí. 
"Assim a finitude, de início, também está na determinação da realidade. Mas a verdade do finito é, antes, sua idealidade" (ibid., p. 193).

Aqui temos o ser-aí, enquanto "qualidade consumada" (isto é, o ser-para-si: realidade e idealidade do ser), como a categoria real de início da lógica. Diferente do ser puro, (enquanto pura abstração) vazio de conteúdo [Inhalt], o ser-aí, em sua determinidade qualitativa é tanto completo de conteúdo [Inhalt], quanto o seu conteúdo é mutável já que, enquanto proporção do todo, o ser-aí ainda possui outras determinações de conteúdo (por exemplo, quantidade e medida) no ato do processo lógico. À vista disso, temos, de um lado, o início determinado (início real), o ser-aí e, de outro lado, temos o vir-a-ser como início procedural (o início como base) da ciência. Esse início enquanto a base do processo lógico é aquilo que Hegel considera como sendo o "conteúdo [Gehalt] total", o "primeiro verdadeiro" (HEGEL, 2016, p. 73) ou, se quisermos, a ideia lógica. Embora a ideia lógica só possa ser dita (evidenciada) em ato (isto é, na imanência do pensar do pensamento puro, e a cada etapa e desdobramento desse processo), por meio das determinações de conteúdos [Inhalte] lógicos, o "sintoma estrutural" desse dito, se é possível assim dizer, é o que é a sua base. Como exemplo, o "sintoma estrutural" do ser-aí, isto é, a sua verdade, é o vir-a-ser que esteve como "sombra" de determinação (aparecer) e consumação (perecer) qualitativa desse ser-aí. É nesse sentido que Hegel, no início da Ciência da lógica, afirma que "o conteúdo [Gehalt] que falta nas formas lógicas não é outro senão uma base e uma concreção firmes dessas determinações abstratas" (ibid., p. 50).

Todavia, no que tange ao problema do início da ciência, a distinção e relação entre Gehalt e Inhalt não é algo fácil de se demonstrar. Primeiro, porque esta diferenciação é apenas implícita na Ciência da lógica e, segundo, porque os conteúdos [Inhalte] lógicos já possuem em si um conteúdo [Gehalt] total, embora essa totalidade apareça suprassumida na proporção. Nesse sentido, temos ainda duas questões em jogo: 1) como podemos pensar o método lógico de Hegel tendo por fio condutor a relação e diferenciação entre Gehalt e Inhalt? 2) por que o ser puro do início é, segundo Hegel, o indeterminado, vazio de conteúdo [Inhalt] se, por outro lado, ele é deduzido como o conteúdo [Gehalt] resultado da ciência do espírito, o saber puro?

\section{A LÓGICA DO CONTEÚDO}

Uma vez pensada a lógica como a ciência do pensamento em geral, é uma tendência comum compreender que este pensamento geral constitui pura e simplesmente um aspecto formal do conhecimento e que o seu dispositivo lógico se abstrai, enquanto método formal, de todo o conteúdo o qual, por sua vez, necessita ser colocado de outro modo. Ocorre que, uma vez alheia ao conteúdo ou material do seu saber, a lógica é apenas capaz de demonstrar as condições formais do conhecimento autêntico, "mas não pode conter a própria verdade real e tampouco pode ser o caminho para a verdade real, porque justamente o essencial da verdade, o conteúdo, está fora dela" (HEGEL, 2011, p. 46). Definir a lógica deste modo implica assumir, portanto, que essa separação definitiva entre a forma do 
conhecimento e o conteúdo dele edifica o método lógico como sendo um mero subjetivismo, cuja finalidade última se reduz a ensinar regras ao pensamento subjetivo, sem se envolver no mérito daquilo que é pensado.

Para Hegel, todavia, esta consciência comum sobre o que seja a lógica é fundamentalmente equivocada. Em primeiro lugar, se a lógica é admitida como a ciência do pensamento em geral, então tanto o pensamento quanto as regras do pensamento devem ser seu objeto. Em segundo lugar, é outro equívoco pressupor que o material do conhecimento está dado em si e para si "como um mundo acabado" e "fora do pensar" (HEGEL, 2016, p. 46), assim como o contrário também é equivocado pensar, isto é, que o pensamento é um reservatório inicialmente análogo a um copo vazio que aos poucos se preenche de uma certa substância e, assim, conquistando um conteúdo, torna-se um meio útil a uma finalidade que lhe é exterior. Em terceiro lugar, sendo a lógica uma ciência do pensamento nestes termos separatistas entre forma e conteúdo, é inegável que uma certa hierarquia é imposta sob um dos lados e, neste caso, o lado do objeto ocupa o topo da pirâmide: ele é tratado como "algo para si consumado, acabado, que poderia dispensar perfeitamente o pensar para sua efetividade” (HEGEL, 2016, pp. 46-47). Já o pensamento, por sua vez, seria precário, vacilante e inacabado, "algo deficiente, que primeiro deveria se completar com um material e, na verdade, como uma forma dócil e indeterminada, deveria se adaptar ao seu material" (HEGEL, 1986a, p. 37). Nesta colocação hierárquica a verdade não seria outra coisa senão uma anuência entre o objeto em si e o pensamento, ou, como diz Hegel, "seria um ajuste do pensamento em relação ao objeto" (id.). Em quarto lugar, sendo o objeto e o pensamento, a forma e o conteúdo registros determinados e separados um do outro, do lado do pensamento, a este não é dada a possibilidade de ultrapassar a si mesmo, tampouco tornar-se seu outro, haja vista que no processo de recepção e enformação [Formieren] da matéria (HEGEL, 2016, p. 47) o pensamento modifica a si mesmo, no sentido de "sair de si mesmo" e o objeto: "este permanece, enquanto uma coisa em si, pura e simplesmente um além do pensar" (id.).

Além de se tratar de um equívoco, Hegel considera ainda que este modo de definição da lógica é responsável por rebaixar o saber ao mero status de opinião, na medida em que tais determinações "constituem a natureza da consciência comum, de nossa consciência que aparece" (HEGEL, 2016, p. 47). Tais juízos, uma vez transpostos para a razão, implicam prejuízos "dos quais a filosofia é a refutação através de todas as partes do universo espiritual e natural” (id.). Ao dizer isso, Hegel está dimensionando a sua crítica com base na sua compreensão do conceito de "entendimento reflexionante" de Kant. Para Hegel, este entendimento reflexionante, que se reduz à mera função do abstrair, separar e fixar a separação, se acomoda como "entendimento humano comum", na medida em que "faz valer sua concepção de que a verdade repousa na realidade sensível, que os pensamentos são apenas pensamentos, no sentido de que somente a percepção sensível lhes dá teor [Gehalt] e realidade" (HEGEL, 2016, p. 48). Este caráter fenomênico atribuído ao saber científico, isto é, de que as coisas são para o entendimento humano algo distinto daquilo que elas são em si mesmas, e que a 
coisa em si [Das Ding an sich] não pode ser conhecida é a renúncia patente da razão em si mesma, um afastamento expressivo do conceito de verdade. Pois, nesta condição, "a razão fica restrita a conhecer somente a verdade subjetiva, apenas o fenômeno [Erscheinung], apenas aquilo a que não corresponde à natureza própria da Coisa (ibid., p. 49).

A despeito disso, Hegel considera que a metafísica antiga possuía uma noção de verdade mais proeminente e menos equivocada do pensamento, pois ela não arvorava o objeto do saber à sua imediatidade, mas antes elevava o objeto à forma do pensamento:

Essa metafísica considerava que o pensar e as determinações do pensar não fossem algo estranho aos objetos, mas antes fossem a essência deles ou que as coisas [Dinge] e o pensar [Denken] deles (assim como também a nossa língua expressa um parentesco entre esses dois termos) concordam em si para si, que o pensar em suas determinações imanentes e a natureza verdadeira das coisas fossem o único e o mesmo conteúdo (HEGEL, 2016, p. 48).

É claro que Hegel não é ingênuo a ponto de não reconhecer que sob as bases desta inflexão do conceito de entendimento reflexionante, repousa a "elevação da razão ao espírito mais alto da filosofia" (id.) do Idealismo Alemão, ainda que de modo negativo, isto é, ainda que a partir da renúncia da razão considerada em si mesma. Para Hegel, o avanço positivo em direção à verdadeira concepção da razão foi a intelecção kantiana da necessidade da antinomia. No entanto, Kant não conseguiu captar o significado positivo-racional da contradição dialética. Dar corpo ao irresoluto por meio da existência sensível, isto é, se refugiar na percepção sensível das coisas sem considerar o que há de unificador no entendimento reflexionante é, na visão de Hegel, assumir que aquilo que não se resolve na contradição só pode encontrar fixação no sensível. Mais do que isso, é assumir igualmente que a coisa em si não pode ser conhecida de modo adequado.

Hegel considera "absurdo um conhecimento verdadeiro que não reconheceria o objeto tal como ele é em si". Para ele "isso não pode ter outro sentido senão que essas formas são nelas mesmas algo não verdadeiro" (HEGEL, 2016, p. 49), pois, se as formas do entendimento não podem ter acesso à coisa em si então elas não podem, igualmente, ser determinações do entendimento. Do mesmo modo, se estas formas do entendimento, ao determinarem como infinitas ou finitas as nossas representações de mundo, incidirem na dissolução de ambos os lados - tal como o vermelho e o branco ao serem misturados se transformam no rosa - então elas são em si mesmas a evidência plena de que o espírito, o qual contém em si ambas as determinações do finito e do infinito, é em si mesmo contraditório e nulo. Desse idealismo kantiano decorre, ao mesmo tempo, outra observação importante feita por Hegel, no que diz respeito à relação entre a forma e o conteúdo da lógica, qual seja, o fato de que uma diferença ou separação entre a forma do pensamento e o conteúdo do objeto conhecido "não pode ser constituída devido à constituição da matéria ou do objeto sobre o qual seriam aplicadas" (id.) as determinações formais, pois o objeto ou o material "possui a 
contradição nele somente por meio de e segundo aquelas determinações formais" (HEGEL, 1986a, p. 41). Isso quer dizer que os conflitos necessários implicados nas determinações do entendimento - seja em relação ao impasse colocado sobre a coisa em si, seja em relação ao problema da dissolução do espírito por meio das determinações do finito e do infinito - encontram sua raiz na ausência de um pensamento objetivo [objektives Denken] sobre as coisas. Isto é, o problema colocado sobre a impossibilidade do conhecimento da coisa em si é derivado da maneira subjetiva como o conteúdo das coisas é tratado: não de modo interno, como deveria (o conceito da coisa ela mesma), mas de modo externo (a coisa como dado sensível).

Esse tratamento subjetivo atribuído ao conteúdo das coisas tem outra consequência importante, no fato de que o entendimento reflexionante mantém separado o que em si e para si deveria se manter unido - isto é, o conteúdo objetivo das coisas e o conteúdo do pensamento - enquanto que, por outro lado, mantém unido aquilo que deveria se manter separado: a forma do objeto e a forma do pensamento. Ou seja, o modo fenomênico com que o entendimento trata a relação entre a forma do pensamento e o conteúdo das coisas faz perder de vista o fato de que o conteúdo das coisas objetivas não é oposto, mas sim um só, junto ao conteúdo do pensamento uma vez que "o pensar em suas determinações imanentes e a natureza verdadeira das coisas são um e o mesmo conteúdo" (HEGEL, 2016, p. 48). Por outro lado, o objeto tratado de modo meramente subjetivo transmuta em forma de sujeito a natureza objetiva da coisa, uma vez que o fenômeno constitui a coisa exatamente tal como a experimentamos, de modo que a sua essência mesma se mantém completamente fora do processo do conhecimento. Isso quer dizer que, apesar de ter aparência de clareza e objetividade, o entendimento, uma vez tratado segundo a lógica subjetiva, é muito mais conflitante e contraditório do que determinante da verdade, seja porque reduz a forma objetiva à forma subjetiva, seja porque não faz frente de modo satisfatório ao problema da coisa em si.

Isso quer dizer ao mesmo tempo que o pensamento objetivo é, segundo a compreensão de Hegel, o conteúdo da ciência pura. Dizer isso, todavia, exige de nós uma distinção importante sobre a relação entre forma e conteúdo, no que se refere propriamente ao conteúdo das coisas e sua materialidade expressiva. Hegel é enfático quanto a esta distinção, pois é exatamente dela que se deriva a adequação autêntica entre o método abstrato do conhecimento e a sua concretude e efetividade. Quando Hegel afirma que a "ciência, no estado em que ainda se encontra, não possui certamente nenhum conteúdo do tipo que vale como realidade e como uma Coisa verdadeira na consciência comum" (ibid., p. 50), isso não quer dizer que a ciência deva ser tratada como ciência formal "desprovida de uma verdade de conteúdo pleno". Por outro lado, também "não é culpa do objeto da lógica se ela deve ser sem de conteúdo, mas apenas da maneira como o mesmo é apreendido" (HEGEL, 2016, p. 51). O que Hegel intenta mostrar é que, uma vez tendo sido levada a sério a consideração da ciência pura por meio de "postura subjetiva", perdeu-se de vista a dimensão do conteúdo envolvido nas formas lógicas. E, ao tratar o conteúdo objetivo como mero elemento formal de percepção 
sensível, esvaziou-se de sentido o que de fato importa para a ciência pura na sua relação necessária com o objeto do seu saber. Para Hegel, na medida em que essas formas lógicas se cindem como determinações firmes e não se sustentam enquanto unidade orgânica em relação à objetividade,

elas são formas mortas e o espírito não habita nelas, espirito o qual é sua unidade concreta que vive. Mas, com isso, elas estão desprovidas do conteúdo sólido - de uma matéria que fosse nela mesma um conteúdo [Gehalt]. O conteúdo que falta nas formas lógicas não é outro senão uma base e uma concreção firmes dessas determinações abstratas; e costuma-se procurar uma tal essência substancial para elas fora delas. A própria razão lógica, porém, é o substancial ou o real, que mantém unidas em si todas as determinações abstratas e que é a unidade sólida, absolutamente concreta delas. (HEGEL, 2016, pp. 50-51).

Mas o que Hegel quer dizer exatamente quando afirma que a ciência pura, para ter uma base e uma concreção firmes, precisa "de uma matéria que seja nela mesma um conteúdo [Gehalt]"? Para responder essa questão é preciso diferenciar os dois sentidos em que Hegel faz uso do termo "conteúdo", o qual traduz duas palavras em alemão: Inhalt e Gehalt. O texto lógico de Hegel não explicita essa diferença no uso dos dois termos. Todavia, o texto nos autoriza a supor essa diferenciação como forma de compreensão da razão lógica hegeliana.

Concordamos com Werle (in HEGEL, 2001a, p. 12) que a "diferença entre os dois termos não é fácil de ser estabelecida em Hegel". Nos Cursos de estética (HEGEL, 2001a, pp. 27-81), por exemplo, Hegel frequentemente usa Gehalt quando quer se referir ao conteúdo do espírito em geral, o qual já se encontra mediado por um estado de mundo, atribuído ao processo de determinação de algo singular. Já o termo Inhalt é frequentemente usado para situações de determinações simples, singulares ou particulares. Por exemplo, o Inhalt de uma obra de arte particular não é a cor, o som, o mármore, etc., mas o seu tema, a sua mensagem, assim como o Inhalt de um livro seria a sua forma interna, sua temática literária, e não a matéria de que ele é feito. Nesse sentido, Inhalt seria sinônimo de Materie (material interno, tema, mensagem, etc.) no horizonte da relação forma e conteúdo de objetos singulares. Assim, na estética, o significado autêntico da obra de arte tem muito menos a ver com a singularidade do objeto e muito mais a ver com a "aparência sensível da ideia" (HEGEL, 2001, p. 126), isto é, com o conceito da obra de arte em geral; o singular seria apenas o momento da encarnação de um conteúdo universal (e historicamente orientado), neste caso, Gehalt, que seria a "ideia de arte". Michael Wood (1997, p. 152) defende algo parecido ao afirmar que, em Hegel, Gehalt se difere de Inhalt na medida em que o primeiro enfatiza algo mais geral, "o valor do conteúdo" (sua "importância"), enquanto o segundo demarca o horizonte da relação forma e conteúdo de objetos singulares. Wood defende igualmente que "Hegel usa mais comumente Inhalt para matéria" [Materie] (ibid., p. 151) em seu sistema de filosofia.

No caso da Lógica, a diferença entre Gehalt e Inhalt é outra, já que se trata de ciência pura, de pensamento puro, que não se relaciona com nenhuma coisa 
[Ding] singular, embora o pensamento puro possua o seu tema (o seu Inhalt) e a sua base de concreção (o seu Gehalt). Na Lógica, a expressão do pensamento puro e do ser puro até pode ser tratada como sensibilização, mas com a ressalva de que, frente ao caráter processual do ser e do pensar, se mostre como sensibilização que se dissolve imediatamente em si mesma (aparece e perece), sem perder de vista, porém, o sentido (a essência) e a base de concreção (a ideia lógica) das formas lógicas e suas determinações abstratas. Nesse horizonte, Inhalt deve ser entendido como sendo o conteúdo ou a matéria [Materie] fluida, mutável, que se movimenta de acordo com sua lógica interna (sua essência: o motor do ser), um tal conteúdo que se nega a "permanecer isolado em sua singularidade" (HEGEL, 1995, p. 70), por isso aparece e desaparece, imediatamente; é o passar, do ser ao nada, ao vir a ser.

A última figura de travessia do ser, enquanto "reflexão nossa", é a passagem do ser como tal, em sua integralidade, à essência. "Na essência, o transitar não tem mais lugar, mas somente a relação" (ibid., p. 219). Sumariamente, no âmbito da essência, o que era travessia se torna relação, a processualidade torna-se reflexividade. O ser em relação consigo mesmo pressupõe o outro de si, a essência, que é o ser posto, mediatizado. A convergência ou identidade entre o ser imediato (em sua integralidade: ser, nada e devir) e a mediação (ser posto: essência) é o conceito junto de si mesmo. O progredir desse conceito, por sua vez, já não é mais nem o passar (esfera do ser), nem o aparecer no outro (esfera da essência), mas "é o desenvolvimento, pelo qual só é posto o que em si já está presente" (ibid., p. 294). Em outras palavras, o conceito é a "identidade consigo" é a "totalidade de cada um dos momentos" (do ser e da essência); e todos os momentos é o que o conceito mesmo é. Na identidade consigo, "o conceito é o determinado em si e para si", é "a plenitude de todo conteúdo" [Inhalt].

Gehalt é, portanto, a plenitude de todo Inhalt, a "base" e a "concreção" das "formas lógicas". Ele é a razão lógica mesma, é o conteúdo "substancial ou o real, que mantém unidas em si todas as determinações abstratas e que é sua unidade sólida, absolutamente concreta" (HEGEL, 2016, p. 50). Quando Hegel afirma que "a lógica, desse modo, precisa ser apreendida como o sistema da razão pura, como o reino do pensamento puro", e que "esse reino é a verdade, como ela é sem invólucro em e para si mesma" (HEGEL, 2016, p. 52), ele está considerando que esse "reino do puro pensamento" é, igualmente, pensamento objetivo. Como nos lembra Walter Jaeschke (2016, p. 208), ao pensamento objetivo não compete mostrar como a objetividade é constituída, e "como a experiência é possível sob a condição prévia das determinações lógicas, reconhecidas como determinações do pensamento, como realizações da subjetividade". Ao contrário, o pensamento objetivo "só se preocupa com o conhecimento destas disposições em si mesmas: como elas são em si mesmas". Desse modo, a Lógica não visa nenhuma exposição totalizante do sentido, mas tão somente a gramática condutora dessa totalidade.

Se, por um lado, o conteúdo [Gehalt] da ciência pura deve ser compreendido como a gramática geradora dos conteúdos [Inhalte] lógicos, por outro lado, essas formas lógicas são, em sua progressão, a fundamentação e evidenciação desse conteúdo [Gehalt] total; elas são, se é possível assim dizer, a 
fundamentação do fundamento. É nesse sentido que Hegel fala da progressão lógica enquanto "retroação e fundamentação" do "primeiro verdadeiro" (HEGEL, 2016, p. 73): a ideia lógica, o conteúdo total. Como já foi dito, a natureza do saber científico não é um pressuposto (enquanto propriedade exclusiva do sujeito ou da coisa [Ding]), mas sim um processo que precisa ser desenvolvido, de modo que o desdobramento de cada momento desse processo se evidencia como fundamentação da ideia lógica. Trata-se, em última instância, de um movimento circular, cuja dinâmica é a da autofundação por intermédio da autoprodução do discurso lógico.

Mas, se a ideia lógica é imanente à exposição processual de conteúdos [Inhalte] lógicos, ou (para usar uma metáfora bem conhecida de Hegel), se "apenas ao cair das sombras da noite é que alça voo o pássaro de Minerva" (HEGEL, 1997, p. 39), então, qual a garantia podemos ter, no começo da Lógica, de que o seu início é pautado por um conteúdo [Gehalt] total, firme e consistente? A compreensão do lugar da Fenomenologia no sistema de Hegel nos ajuda a esclarecer essa questão.

\section{A FENOMENOLOGIA DO ESPÍRITO COMO PRESSUPOSIÇÃO DA CIÊNCIA DA LÓGICA}

Segundo a perspectiva de Walter Jaeschke (2016, p. 208), a Fenomenologia do Espírito de Hegel (embora inclua um ensinamento espiritual) é, reconhecidamente, uma "introdução" ao seu sistema da lógica - não no sentido de uma abordagem dialética dele, mas sim de sua justificação conceitual e histórica. Ao realizar a "libertação da oposição da consciência", e elevar as determinações de pensamento acima do registro subjetivo, a Fenomenologia resultou, segundo Jaeschke, no conceito de "pensamento objetivo", em "pensar na medida em que é a coisa em si"; e "este pensamento objetivo é então o conteúdo [Gehalt da ciência pura”. Numa abordagem bastante próxima, Kervégan (2017, p. 193) defende que o saber absoluto "delimita o espaço dentro do qual o saber será capaz de se desenrolar como ciência do "verdadeiro que está na forma do verdadeiro". No entanto, acrescenta Kervégan, "somente o sistema desenvolvido em sua totalidade (a Enciclopédia das ciências filosóficas) pode estabelecer o que já está, por assim dizer, totalmente presente na sua propedêutica" (a Fenomenologia). Christian Iber (2017, p. 82) também considera que "a Fenomenologia do espírito tenha para Hegel uma função introdutória, propedêutica à Ciência da lógica”. Todavia, defende Iber, teórico-validacionalmente a Lógica é uma ciência sem pressupostos; isso porque ela pode se fundamentar reflexivamente a si mesma. Assim sendo, a pressuposição da Lógica (a qual se refere a Fenomenologia) "é apenas que são suprasumidas pressuposições falsas, dentre outras a assim chamada oposição da consciência do sujeito e do objeto" (id).

De fato, na primeira parte da Ciência da lógica (a 'Doutrina do ser'), Hegel chega a afirmar que a Lógica tem "como a sua pressuposição a ciência do espírito que aparece, a qual contém e mostra a necessidade e, com isso, a prova da verdade do ponto de vista que é o saber puro, assim como sua mediação em geral" (HEGEL, 2016, p. 71). Para o nosso autor, assim como na Lógica, na Fenomenologia "a 
consciência imediata é também o que é primeiro e imediato na ciência, ou seja, a pressuposição. No entanto, na Lógica, a pressuposição é o que se demonstrou como resultado" da Fenomenologia: "a ideia como saber puro" (id.). Nesse sentido, para Hegel, a pressuposição da Lógica não é exatamente "o espírito que aparece" no percurso fenomenológico da consciência, mas sim o resultado do seu percurso: "a ciência do espírito", a "ideia como saber puro". Do mesmo modo, a "ciência do espírito" (a qual Hegel se refere nesta parte do texto) não se confunde com o seu desenvolvimento no sistema (a filosofia real); aqui Hegel se refere tão somente à ideia desse desenvolvimento, à ideia como começo, como filosofia primeira (Lógica). Ao contrário da Fenomenologia, a "consciência imediata" da Lógica é tão somente aquilo que é "imediato na ciência": a ideia lógica. Se considerarmos o dualismo implicado na Fenomenologia, isto é, o que a consciência é para si mesma e o que ela é "para nós", se é possível assim dizer, o que Hegel avalia como sendo a pressuposição da Lógica é apenas o "para nós", ou seja, a cientificidade que se demonstrou como superação da oposição entre sujeito e objeto. Assim, a pressuposição da lógica é o conceito de "pensamento objetivo", "deduzido" pela Fenomenologia.

Todavia, Hegel trata em sua lógica enciclopédica (especificamente, no 'Conceito preliminar da Lógica') de outra pressuposição, agora justificada pela sua leitura acerca das principais correntes filosóficas do pensamento ocidental. À vista disso, a dedução do conceito de lógica implementado por Hegel é derivada de um exame histórico da lógica na filosofia. Ele analisa, sobretudo, as teses fundamentais da metafísica (escola de Wolff), do empirismo (de Hume), da filosofia transcendental (de Kant) e do conhecimento imediato (de Jacobi), com o objetivo de evidenciar o significado do seu ponto de vista atribuído ao conceito de lógica, em detrimento às "posições conferidas ao pensar a respeito da objetividade" (HEGEL, 1995, p. 87).

No "Conceito preliminar da Lógica", Hegel justifica essa necessidade ao declarar que, no âmbito da sua Fenomenologia, as determinações de pensamento não receberam a sua plena solução; que somente ocorrerá na Lógica. Segundo Hegel, na Fenomenologia, o desenvolvimento da consciência pressupõe, ao mesmo tempo, as suas "figuras concretas" (a moral, a ética, a arte, a religião), uma vez que ela (a consciência), para desenvolver-se até a perspectiva da ciência filosófica, não poderia se manter no formal simples da consciência. E mais, sendo a ciência filosófica também a mais rica de conteúdo e a mais concreta, "o desenvolvimento do conteúdo, dos objetos que são partes próprias da ciência filosófica, incide ao mesmo tempo nesse desenvolvimento da consciência" (HEGEL, 1995, p. 88). Mas esse desenvolvimento, acrescenta Hegel, precisa "avançar por detrás da consciência", uma vez que o conteúdo não se relaciona apenas com a consciência, mas igualmente consigo mesmo. Nesse sentido, a Lógica é o desenvolvimento desse conteúdo "em si". Esse conteúdo concreto (pertencente as partes concretas), o qual recai parcialmente nessa introdução à ciência (a Fenomenologia), somente na Lógica recebe a sua verdadeira solução, à medida que é reduzido "à simples determinação de pensamento" (id.). 
Embora essa distinção feita por Hegel pareça esclarecer a questão da compreensão da Fenomenologia enquanto pressuposição da Lógica, a sua posição em relação ao sistema de ciência se mantém (segundo a visão de alguns intérpretes) como algo de controverso. Há pelo menos três razões para isso, segundo Kervégan (2017, pp. 196-97): primeiro, porque "a organização final do sistema de filosofia de Hegel elimina a Fenomenologia como sendo a sua introdução ou primeira parte". Segundo, porque "em sua versão enciclopédica, a Lógica possui a sua própria introdução científica ('O conceito preliminar da Lógica'), pautada não nas figuras da consciência e do espírito, mas na crítica às principais correntes do pensamento ocidental. Terceiro, porque a Fenomenologia do espírito passa a compor, no sistema enciclopédico, a filosofia do espírito (a 'Doutrina do espírito subjetivo'), portanto, sistematicamente posterior à Lógica. De fato, na introdução da Enciclopédia de 1817, Hegel elimina a Fenomenologia como sendo a sua introdução ou primeira parte do sistema ao afirmar que, "embora costumava tratar a Fenomenologia "como a primeira parte da filosofia, no sentido de que ela deve preceder a ciência pura, uma vez que é a produção do seu conceito. Por outro lado, era preciso reconhecer que "a consciência, e a sua história, como qualquer outra ciência filosófica, não é um começo absoluto, mas um elo no círculo da filosofia." (HEGEL, 2001b, p. 34).

Essa aparente mudança de perspectiva de Hegel resultou em desacordos entre os comentadores hegelianos. Como ressalta Kervégan (2017, pp. 194-95), Theodor Haering, com base nas divisões de capítulo e no conteúdo da Fenomenologia, sustentou que Hegel teria mudado de compreensão durante o processo de redação da obra, uma vez que acrescentou elementos (O Espírito, A Religião e o Saber absoluto) "que não fazem mais dela uma 'ciência da experiência da consciência' propedêutica, mas antes uma primeira parte do sistema" (Hearing, 1929;1938 apud Kervégan, 2017, p. 194). Todavia, Otto Pöggeler contesta a tese de Haering, sobretudo, pelo fato de Hegel republicar a Fenomenologia sem, contudo, fazer modificações consideráveis em suas divisões e conteúdos (Pöggeler, 1985, pp. 145-192 apud Kervégan, 2017, p. 195). Já para Karl Rosenkranz, a Fenomenologia, "por se tratar de um ato de tomada de consciência, por Hegel, de sua originalidade filosófica, ela é, neste sentido, tanto uma introdução ao sistema quanto sua primeira parte". (Rosenkranz, 2004, p. 338 apud Kervégan, 2017, p 195). À vista disso, a posição de Kervégan (ibid., p. 194) é mediadora: embora ele reconheça, por um lado, que a Fenomenologia expressa "o mesmo conteúdo que o sistema enciclopédico desenvolvido, mas segundo uma outra ordem de significação", por outro lado, ele ressalva que, "sem dúvida, há um desnivelamento entre a Fenomenologia e o sistema". Nesse sentido, Kervégan concorda com Pöggeler que "a ideia da fenomenologia é um pensamento com o qual Hegel lutou, sem cessar, desde seus primeiros anos em Jena até o fim de sua vida" (Pöggeler, 1985, p. 191 apud Kervégan, 2017, p. 199).

Dizer que Hegel tenha mudado de perspectiva durante o processo de redação de sua Fenomenologia (como defende Haering), de fato, parece não ser o caso, haja vista as diversas justificações (como vimos anteriormente) do próprio Hegel em relação a posição desta obra no seu sistema de ciência. Nesse aspecto, 
concordamos com a interpretação de Pöggeler. Do mesmo modo, concordamos com Kervégan que, tanto Hegel tenha abandonado "a denominação "primeira parte" (KERVÉGAN, 2017, p. 199), ao se referir ao lugar da Fenomenologia no sistema, quanto que ela expressa o mesmo conteúdo que o sistema enciclopédico em sua totalidade. No entanto, discordamos de que haja um desnivelamento entre a Fenomenologia e o sistema, considerando as três razões de impasse interpretativo (apontadas por Kervégan) anteriormente descritas, sobretudo, a terceira delas: a de que a Fenomenologia do espírito passa a compor, no sistema enciclopédico, a filosofia do espírito (a 'Doutrina do espírito subjetivo'), portanto, sistematicamente posterior à Lógica. Como já foi dito, quando Hegel afirma (e isso ele sustenta até o fim) que a Fenomenologia do espírito é a introdução, a pressuposição, ou, até mesmo, a justificação [Begründung] da Lógica, ele está se referindo ao resultado da Fenomenologia (o saber absoluto enquanto saber puro), e esse resultado é compatível tanto com o fato de a Lógica ser a ciência primeira no curso do sistema, quanto com o fato de a Fenomenologia do espírito ser (no âmbito do sistema enciclopédico) um desenvolvimento posterior ao discurso lógico. Para além dos argumentos de Hegel até aqui apresentados acerca dessa questão, há uma última justificação de Hegel (aliás, pouco citada pelos intérpretes), a qual serve para reforçar a nossa posição. Convém lembrar que esta explicação é a última proferida por Hegel, no âmbito da sua última preleção sobre a Ciência da lógica [as Vorlesungen über die Wissenschaft der Logik], no verão de $1831^{6}$ (ano de seu falecimento):

o resultado da ciência é o conceito de ciência e esta é a base da ciência. Na doutrina da Fenomenologia do espírito é considerado o movimento da consciência, a verdade última é o conhecimento puro, a compreensão do pensamento, e esta última começa com o ser em geral: este conhecimento último é então a justificação deste começo; mas esta justificação é encontrada no progresso e este progresso também está em declínio. Assim, em análise, pode-se defrontar com a diferença, com o infinitamente grande e pequeno, etc., e não se chegará a lado nenhum desta forma. É preciso avançar, de modo que o que se segue se torna claro, e o mesmo acontece com o início: tanto mais que, tendo em conta estes princípios abstratos, o devir é a verdade do ser e do nada (HEGEL, 2015, pp. 723-24).

Considerando, portanto, o resultado da Fenomenologia do espírito enquanto justificação do saber puro, temos, então, pelo menos três "fios condutores" (que são consistentes e harmoniosos entre si) daquilo que significa "o pressupor" da ciência pura enquanto ciência primeira no curso do saber: 1) na lógica enciclopédica, a pressuposição é deduzida da análise da lógica na história da filosofia; 2) na Ciência da lógica, por um lado, o conhecimento puro, o

\footnotetext{
${ }^{6}$ Hegel ofereceu oito cursos da Ciência da lógica ao longo de trinta anos. O primeiro deles (intitulado de Cursos sobre lógica e metafísica) ocorreu em 1801/02, em Jena, e apenas o caderno de anotações de um dos seus alunos (desse semestre), Ignaz Paul Vital Troxler, foi recuperado, editado e recém publicado pelo projeto editorial das obras coletadas de Hegel (Gesammelte Werke). Sobre esse primeiro curso cf. HEGEL, 2013, pp. 13.20. Os demais cursos ocorreram nos anos de 1817, 1823,1824, 1825, 1826, 1828, 1829 e, o último, o qual aqui fazemos referência, correu em 1831 em Berlim. O caderno anotações desse último curso foi copiado pelo filho de Hegel, Friedrich Wilhelm Karl Ritter von Hegel, quem acompanhou o último curso sobre a Ciência da lógica, no ano de seu falecimento do pai. Sobre esse último curso cf. HEGEL, 2015, pp. 437-809.
} 
pensamento objetivo (resultado da Fenomenologia) é o pressuposto, contudo, por outro lado; 3) a ideia lógica é, igualmente, engendrada por si mesma em seu processo.

\section{CONCLUSÃO}

Dizer que a Ciência da lógica possui como pressuposto de início o pensamento objetivo (mas que esse saber puro, ao mesmo tempo, é a ideia lógica que precisa ser engendrada no interior do processo das determinações de pensamento) corresponde à afirmação de que o saber lógico, na visão de Hegel, é algo histórico e conceitualmente compartilhado, embora a sua evidenciação só possa ser escrita à medida que, no âmbito do lógico-especulativo, o saber objetivo progressivamente deixa de ser imediato para ser posto, no sentido de refletido e re-conhecido. Segundo Hegel, essa ideia lógica, em sua completude de determinações, "pode-se comparar ao ancião que pronuncia as mesmas asserções religiosas que a criança, mas que tem para ele a significação de toda a sua vida" (HEGEL, 1995, p. 367). Essa asserção descarta, todavia, a impressão de que os conteúdos [Inhalte] lógicos são cegos no início do sistema, no sentido de que a sua verdade só pode ser atingida ao final do processo. Pois, se por um lado, o conteúdo [Inhalt] da ideia absoluta é o desdobramento de todo o processo, por outro lado, entretanto, esse "conteúdo [Inhalt é o desenvolvimento vivo da ideia"; e a sua determinação progressiva já está contida nessa ideia desde o início (id.).

A diferença do início em relação ao final do processo lógico é que, no começo, a ideia é em si e, no final, ela é em si e para si, é a ideia determinada e evidenciada como ideia absoluta. Na visão de Hegel, o que justifica o método lógico enquanto determinação processual do conteúdo [Gehalt] total (a ideia lógica), por meio da exposição de conteúdos [Inhalte] lógicos está no fato da deficiência própria da ideia em relação ao seu conhecimento científico. Para Hegel, o que se anuncia no início da Ciência da lógica como ser em si na verdade é a própria ideia total em sua imediatez: "a ideia da vida". A deficiência desta ideia da vida não consiste, no início, no fato de ela ser simplesmente uma opinião subjetiva, uma hipótese analítica, ao contrário, ela é um enunciado objetivo de todas as coisas, um conteúdo total, incluindo o ser sujeito. A deficiência da ideia no início consiste, pois, "em ser apenas a ideia em si essente" (ser-aí), sem determinações de pensamento. Por outro lado, o conhecimento puro, inicialmente, também é uma ideia essente, já que participa desse enunciado objetivo (todas as coisas). Porém esse conhecimento é uma "ideia essente para si" uma vez que, enquanto conhecimento, é conhecimento pensando todas as coisas, logo, pensando a si mesmo. Nesse ato de pensar, tendo por objeto a si mesmo, o ato de conhecer, inicialmente, é unilateral à medida que ainda não se reconhece como ideia essente em si e para si, isto é, que ainda reconhece apenas o pensamento de si como objeto de pensamento (pensamento objetivo), cujo todo (o outro de si: todas as coisas) ainda permanece indeterminado. "A unidade e a verdade dessas duas ideias é a ideia essente em si e para si, e por isso absoluta” (HEGEL, 1995, p. 366). 
Nesse sentido, as determinações lógicas desse conteúdo total são, exatamente, a progressão gradual necessária do pensamento objetivo para além de sua determinidade inicial, de ter a si como objeto de pensamento (ser puro e saber puro), de modo a avançar no pensamento das coisas [Sachen] tal como a si mesmo. Assim, o que está inicialmente fora (o outro de si) do pensamento objetivo (a ideia essente para si) passa, gradualmente, a incorporar o próprio pensamento, cujo final culmina na unidade lógica do todo como sistema total: a ideia absoluta, ou, se quisermos, a maturidade do pensamento como significação de todas as suas determinações de pensamento, na forma lógica. Como se pode notar, a ideia absoluta não está determinada no início, mas isso não quer dizer que ela não esteja pressuposta como o "primeiro verdadeiro" no curso do pensar lógico. Como diz Hegel, cada um dos graus de determinação do processo lógico nada mais são do que "imagens do absoluto", assim como a ideia absoluta não é outra coisa senão que um objeto em torno do qual "vieram reunir-se todas as coisas" (ibid., p. 368).

O sistema lógico é, portanto, um encontro de reconciliação progressiva (por meio das determinações de pensamento) entre o pensamento objetivo e as coisas [Sachen] como totalidade. Essa unidade lógica não se refere, porém, (como já foi dito no início) a coisa [Ding] dada, mas sim ao que é internamente constitutivo na coisa: a sua essência. Assim, o lógico não é um sistema total que compreende a vida inteira, o mundo inteiro, mas é o primeiro sentido (justificado como necessário) totalizante das determinações essenciais e, por isso, a ciência primeira. É a lógica do conteúdo no reino das sombras. As sombras, são justamente essas determinações essenciais: os conteúdos [Inhalt] lógicos, as "imagens do absoluto" (imagens em movimento); o reino, é a base consistente, a "forma infinita", o conteúdo [Gehalt] total no interior do qual as determinações de conteúdos lógicos operam como imagens em movimento. "A ideia lógica é, assim, a forma infinita do seu conteúdo” (HEGEL, 1981, p. 237).

Quando Hegel afirma, como já foi dito, que o conteúdo da lógica é a exposição de Deus, tal como ele é na sua essência eterna, ele não quer dizer que Deus é uma totalidade de sentido, mas, ao contrário, que Deus é uma gramática fundadora do sentido de totalidade. Em última instância, essa gramática de Deus, não é outra coisa senão a gramática da racionalidade, o filosofar especulativo propriamente dito.

\section{REFERÊNCIAS}

BORDIGNON, Michela. Ai limiti della verità: il problema della contraddizione nella logica di Hegel. Pisa: ETS, 2015.

Dialética e dialeteísmo. Evitar a explosão e enfrentar a exclusão. In: BAVARESCO, Agemir et al (eds.). Leituras da Lógica de Hegel II. Porto Alegre, RS: Editora Fi, 2018, pp. 233-252.

BOURGEOIS, Bernard. Hegel: os atos do espírito. Trad. Paulo Neves. São Leopoldo: Unisinos, 2004. 
HAERING, Theodor L. Hegel. Sein Wollen und sein Werk. Band 2. Berlin: Teubner, 1938.

HARTMANN, Klaus. Hegel's Logik. Berlin: Walter de Gruyter, 1999.

HEGEL, Georg W. F. Wissenschaft der Logik. zweiter Band. Die subjektive Logik (1816). Gesammelte Werke. Bd. 12. Herausgegeben von Friedrich Hogemann und Walter Jaeschke. Hamburg: Felix Meiner, 1981.

Enzyklopädie der Philosophischen Wissenschaften im Grundrisse (1817). Gesammelte Werke. Bd. 13. Herausgegeben von Wolfgang Bonsiepen und Klaus Grotsch. Hamburg: Felix Meiner, 2001.

Vorlesungen über die Wissenschaft der Logik I. Nachschriften zu den Kollegien der Jahre 1801/02, 1817, 1823, 1824, 1825 und 1826. Gesammelte Werke. Bd. 23,1 Herausgegeben von Annette Sell. Hamburg: Felix Meiner, 2013.

Vorlesungen über die Wissenschaft der Logik II. Nachschriften zu den Kollegien der Jahre 1828, 1829 und 1831. Gesammelte Werke. Bd. 23,2. Herausgegeben von Annette Sell. Hamburg: Felix Meiner, 2015.

Suhrkamp, 1986.

Wissenschaft der Logik. In: Werke in 20 Bänden, Werke 5 und 6. Frankfurt:

Ciência da lógica 1. A Doutrina do Ser. Trad. Christian G. Iber, Marloren L. Miranda e Federico Orsini. Coordenador: Agemir Bavaresco. Colaboradores: Michela Bordignon, Tomás Farcic Menk, Danilo Costa e Karl-Heinz Efken. Petrópolis: Vozes, 2016.

Ciência da lógica 3. A Doutrina do Conceito. Trad. Christian G. Iber e Federico Orsini. Coordenador: Agemir Bavaresco. Colaboradores: Michela Bordignon, Tomás Farcic Menk, Danilo Costa e Karl-Heinz Efken. Petrópolis: Vozes, 2018.

. Cursos de estética I. Trad. Marco Aurélio Werle. São Paulo: Edusp, 2001.

Princípios da filosofia do direito. Trad. Orlando Vitorino. São Paulo: Martins Fontes, 1997.

Enciclopédia das Ciências Filosóficas em Compêndio (1830) Vol. I (A Ciência da Lógica) Trad.: Paulo Meneses e Pe. José Machado. São Paulo: Loyola, 1995.

HÖSLE, Vittorio. O sistema de Hegel: o idealismo da subjetividade e o problema da intersubjetividade. Trad. Antônio C. P. de Lima. São Paulo: Loyola, 2007.

IBER, Christian. O que Hegel propriamente quer com sua Ciência da Lógica? In: BAVARESCO, Agemir et al (eds.). Leituras da Lógica de Hegel II. Porto Alegre, RS: Editora Fi, 2018, pp. 77-100.

JAESCHKE, Walter. Hegel Handbuch: Leben, Werk, Schule. 3. Auflage. Stuttgart: J.B. Metzler Verlage GmbH, 2016.

KERVÉGAN, Jean-Fraçois. Hegel e o hegelianismo. Trad. Mariana P.S. da Cunha. São Paulo: Loyola, 2005. 
KERVÉGAN, Jean-Fraçois. A Fenomenologia do espírito é a fundação última do "sistema da ciência" Hegeliano? Trad. Nicolau Spadoni e Paulo Amaral. Revista Discurso, vol. 22, n. 4, pp. 187-202, jul./dez. 2017.

MÜLlER, Marcos L. A contradição dialética e sua resolução no fundamento. In: HELFER, Inácio (ed.). Lógica e metafísica em Hegel. São Leopoldo, RS: Ed. Unisinos, 2019, pp. 123-149.

PIPPIN, Robert B. Hegel's Realm of Shadows: logic as metaphysics in the Science of logic. Chicago/London: The University of Chicago Press, 2019.

PÖGGELER, Otto. Qu'est-ce que la Phénoménologie de l'Esprit? In: RÉGNIER, Marcel (ed.). Études hégéliennes. Paris: Vrin, 1985.

ROSENKRANZ, Karl. Vie de Hegel. Paris: Gallimard, 2004.

WANDSCHNEIDER, Dieter. Grundzüge einer Theorie der Dialektik. Rekonstruktion und Revision dialektischer Kategorienentwicklung in Hegels "Wissenschaft der Logik". Stuttgart: Klett-Cotta, 1955.

WOLFF, Michael. Der Begriff des Widerspruchs. Eine Studie zur Dialektik Kants und Hegels. Meisenheim: Hain,1981.

WOOD, Michael. Dicionário Hegel. Trad. Alvaro Cabral. Rio de Janeiro: Zahar, 19997.

Recebido em: 29-02-2020

Aceito para publicação em: 07-08-20 